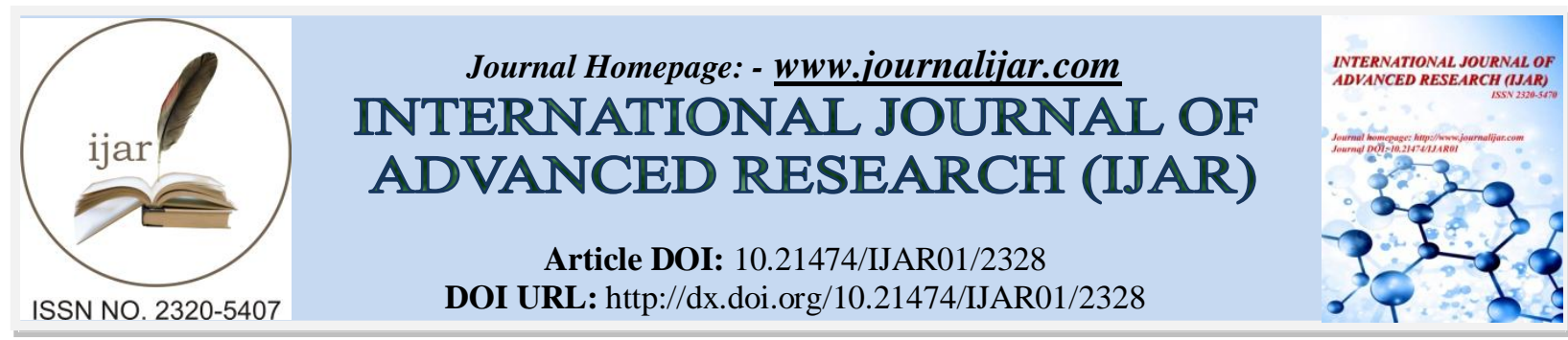

RESEARCH ARTICLE

\title{
DIABETES RELATED EMOTIONAL DISTRESS AND DEPRESSION: A STUDY OF PATIENTS WITH TYPE 2 DIABETES MELLITUS.
}

Urooj un Nisa and Dr. Humera Shafi.

1. Ph. D. Research scholar, Department of Psychology, University of Kashmir, Srinagar (190006).

2. Sr. Asst. Professor, Department of Psychology, University of Kashmir, Srinagar (190006).

\section{Manuscript Info}

Manuscript History

Received: 30 September 2016

Final Accepted: 30 October 2016

Published: November 2016

Key words:-

Type 2 diabetes, Depression, Diabetesrelated distress.

\section{Abstract}

Objective: The purpose of this study was to investigate the relationship between diabetes-related emotional distress and depression in patients with type 2 diabetes.

Methods: A cross-sectional study of 435 adults with type 2 diabetes attending a private clinic at Srinagar city (J\&K). Data on depression and diabetes-related emotional distress rates were collected using the BDI-II and PAID self-reported questionnaires. Pearson's Correlation coefficient and Stepwise multiple regression analyses were performed. Results: Educational status, comorbidity, and duration of diabetes were found to be significantly associated with diabetes related emotional distress and depression and while controlling these variables in the model of stepwise multiple regression, diabetes related emotional distress emerged as significant predictor of depression in type 2 diabetes.

Conclusions: Findings support the routine screening of patients with diabetes for depression and diabetes-related emotional distress. The study can prove helpful to health care specialists who can play a key role in counseling the patients to promote positive behavioural change and supporting self management.

Copy Right, IJAR, 2016,. All rights reserved.

\section{Introduction:-}

Diabetes is a chronic disease which affects virtually every organ in the human system. The World Health Organization projected that 300 million people will suffer from diabetes by 2025 (King, Auburt, \& Herman, 1998). India has the largest number of diabetic population in the world and it is expected that there will be 69.9 million diabetic populations in India by 2025 (King, Auburt, \& Herman, 1998). Self-management is an essential element of diabetes care and refers to the individual's ability to manage symptoms, treatment, physical and psychological consequences, and lifestyle changes inherent to this chronic condition (Barlow, Wright, Sheasby, Turner, and Hainsworth, 2002). Diabetes management requires long-term adherence to diet, physical activity, medication, and frequent monitoring of blood glucose levels, and patients have to learn to integrate self-management into their daily lives and to cope with complications. The continued need for self-management makes patients with diabetes vulnerable to psychological distress, such as depression and emotional distress (Rubin, and Peyrot, 2001). Chronic depression can seriously hamper an individual's ability to take care of everyday responsibilities. The prevalence of depression in patients with type 2 diabetes is significantly higher than that in the general population (Ali, Stone, Peters, Davies, and Khunti, 2006). Compared with patients with diabetes alone, patients with depression and diabetes have been shown to have poorer self-management and are more likely to have higher cardiovascular risk 
factors like smoking, obesity, sedentary lifestyle, and uncontrolled hyperglycaemia (Katon, et al., 2004). People with diabetes can also experience subclinical emotional distress, such as feelings of guilt, frustration, being overwhelmed, anger, or fear (Rubin and Peyrot, 2001). Many people experience considerable distress about having diabetes and the amount of hands-on management that diabetes requires. This often includes frustration with the ongoing obligations of diet, physical activity, blood glucose monitoring and taking medicines. Diabetes emotional distress is a condition distinct from depression that is related to diabetes outcomes (Fisher, et al., 2009). Studies have shown that depression and diabetes-related emotional distress can disrupt self-management (Ciechanowski, Katon, Russo, and Hirsch, 2003) and worsen glycemic control (Lustman, et al., 2000; Lustman, and Clouse, 2005), thereby increasing the risk of complications (Black, Markides, and Ray, 2003; Gonzalez, et al., 2010; Katon, et al., 2004). Risk factors for depression are female gender (Ali, Stone, Peters, Davies, and Khunti, 2006; Pouwer, et al., 2010), age <64 years (Leach, 2012), low education (Egede, and Zheng, 2003), presence of complications (Pouwer, et al., 2003), poor glycemic control (Rubin, and Peyrot, 2001; Lustman, et al., 2000), and insulin treatment (Delahanty, et al., 2007). Also in the United Kingdom, adults with T2DM were, after controlling for age, gender, ethnicity, and socioeconomic status, more likely to suffer from these common mental disorders (Egede, and Zheng, 2003).

Emotional problems might complicate the required self-management of the disease (Aikens, 2012), and limit the persons' management of self-care activities necessary to achieve an adequate glycemic control (Peyrot, McMurry, and Krueger, 1999). The recent DAWN2 study showed that emotional problems are a challenge of concern in persons with diabetes across cultures (Nicolucci et al., 2013).

The presence of depression or diabetes-specific emotional distress, or a combination of these, might comprise barriers to adequate self-management in persons with diabetes (Lloyd, Pambianco, and Orchard, 2010). The underrecognition of emotional problems, such as depression, anxiety, and diabetes-specific emotional distress, has been reported (Pouwer, Beekman, Lubach, and Snoek, 2006), and when such concerns are recognized, problems might be identified as depression, even in patients whose problems are directly related to diabetes and its treatment (Gonzales, Fisher, and Polonsky, 2011). Diabetes-specific emotional distress can be defined as a range of emotional responses and reactions to life with diabetes, especially those related to the treatment regimen and self-care demands. It is part of a person's experience of managing diabetes and its treatment in the social context of family and health-care personnel (Fisher, Hessler, Polonsky, and Mullan, 2012). In contrast, depression is more strongly related to an anhedonic state, in which an individual is markedly affected by feelings of sorrow and hopelessness (Watson et al., 1995; Zigmond and Snaith, 1983)

Gonzales et al. (2008) suggested that depression and diabetes-specific emotional distress are independent constructs in type 2 diabetes, and later proposed that there can be confusion regarding what is actually addressed (Gonzales, Fisher, and Polonsky, 2011). Hermanns et al. (2006) showed that despite some overlap, people with depression and those with diabetes-specific emotional distress did not constitute identical groups in patients within type 1 or type 2 diabetes. It has been shown that depression and diabetes-specific emotional distress are differently associated with diabetes-specific indicators, but this is mainly examined in persons with type 2 diabetes (Fisher, Glasgow, and Strycker, 2010; Fisher et al., 2010; Fisher et al., 2007).

Chew, Vos, Mohd-Sidik, and Rutten (2016) further found that diabetes related distress and depression were correlated. Patients with higher diabetes related distress were younger and had higher scores on the patient health questionnaire.

Efficient psychological care such as cognitive behavioral therapy or medication is available (Pouwer, 2003). Unfortunately the detection rate of depression in patients with diabetes, which is an important condition for treatment, is still low (Pouwer, Beekman, Lubach, and Snoek, 2006). Given the importance of a timely diagnosis and treatment of psychosocial distress, and screening for depression and diabetes-related distress in patients with diabetes should be integrated in structural diabetes care (IDF, 2006; American Diabetes Association, 2006). To support the need for such screening, the aim of this study was to estimate the prevalence of depression and diabetesrelated emotional distress and to investigate relevant risk factors in patients attending a diabetes center.

\section{Objectives:-}

1. To study the relationship between diabetes related emotional distress and depression among type 2 diabetes mellitus patients. 


\section{Methods:- \\ Study population:-}

In this cross-sectional study, 435 patients (selected purposively) with type 2 diabetes attending an outpatient diabetes clinic at Srinagar city of J\&K comprised the sample of the study. Eligibility criteria were age $>18$ years, diagnosis type 2 diabetes with or without comorbidity, and taking insulin and oral drugs for $>1$ year. All eligible patients were told about the study and were invited to participate. Patients who were willing to participate received both written and verbal information about the study, an informed consent form, and questionnaires.

\section{Measurements:-}

Demographic and clinical characteristics, including age (in years), gender, educational level (high education being defined as secondary school or university), and duration of diabetes were assessed by self-report. Information about co-morbidities (thyroidism, heart disease, hypertension and obesity) was obtained from the medical records.

Depression was measured using the Beck's Depression Inventory (BDI- II) (Beck, Steer, and Brown, 1996). It is a 21-item self-report instrument intended to assess the existence and severity of symptoms of depression. The test items are measured on a Likert scale of 0-3. People are asked to report feelings consistent with their own over the past 2 weeks. Interpretation of scores is accomplished through criterion-referenced procedures utilizing the following interpretive ranges: 0-13-minimal depression; 14-19-mild depression; 20-28-moderate depression; and 2963 -severe depression. The test was also shown to have a high one-week test-retest reliability (Pearson $r=0.93$ ). The test also has high internal consistency $(\alpha=.91)$.

Diabetes-related emotional distress was measured with the validated Problem Areas in Diabetes-scale (PAID) by Joslin Diabetes Centre, Boston. Its authors are Polonsky, Anderson, Lohrer, Welch, Jacobson, Aponte, and Schwartz (1995). It consists of 20 items that cover a range of emotional problems frequently reported in type 1 and type 2 diabetes. Each item is rated on a six-point Likert type scale. A total scale score is computed by summing the total item responses. Psychometric reports to date on the PAID have shown it to: (i) have consistently high internal reliability (i.e. a $=0.90)$; (ii) have sound $(r=0.83) 2$-month test-retest reliability using a sample of stable patients. A cut-off score $\geq 30$ is appropriate for detecting clinical and subclinical depression with a sensitivity of $79 \%$ and a specificity of 76\% (Polonsky, Anderson, Lohrer, Welch, Jacobson, Aponte, 1995).

\section{Ethical issues:-}

To adhere the ethical considerations and to reduce biases the study was approved by Departmental Research Committee of University of Kashmir. To assist the subjects to understand the reason for the study, both the information sheet and the questionnaires will be written in two languages (English and Urdu). The information sheet describing the study in the language of subjects' choice and will be given to them to read or will be read to them by the researcher. Written consent will be taken from all the participants before taking the relevant information. Further the researcher will not take any such kind of information which will disclose the participant's identity.

\section{Statistical Analysis:-}

Statistical analyses were performed using SPSS version-20. Pearson's correlation coefficient and stepwise multiple regression was used to investigate the relationship of diabetes-related distress with depression. A p-value of $<0.05$ (two tailed) was considered to be statistically significant in all analyses.

\section{Results and Interpretation:-}

Results revealed that there is significant positive correlation between Depression and Diabetes related emotional distress as correlation coefficient $(r=0.733)$ is significant at $\mathrm{p} \leq 0.01$ level of significance (Table 3 ).

Stepwise multiple regression analyses were carried out to predict depression among type 2 diabetes mellitus patients (Table 4). Diabetes related emotional distress explained 54\% of variance in depression. Together with demographic and clinical variables, final model explaining the total variance of $59.4 \%$ in depression. In this model while controlling the demographic and clinical variables [educational status (beta $=-.172, \mathrm{p}<.001$ ), comorbidity (beta $=$ $.111, \mathrm{p}<.001$ ), duration of diabetes (beta $=.079, \mathrm{p}=.010$ )], diabetes related distress (beta $=.696, \mathrm{p}<.001$ ) emerged as significant predictor of depression in type 2 diabetes mellitus. 
Table 1:- Baseline characteristics of the study population.

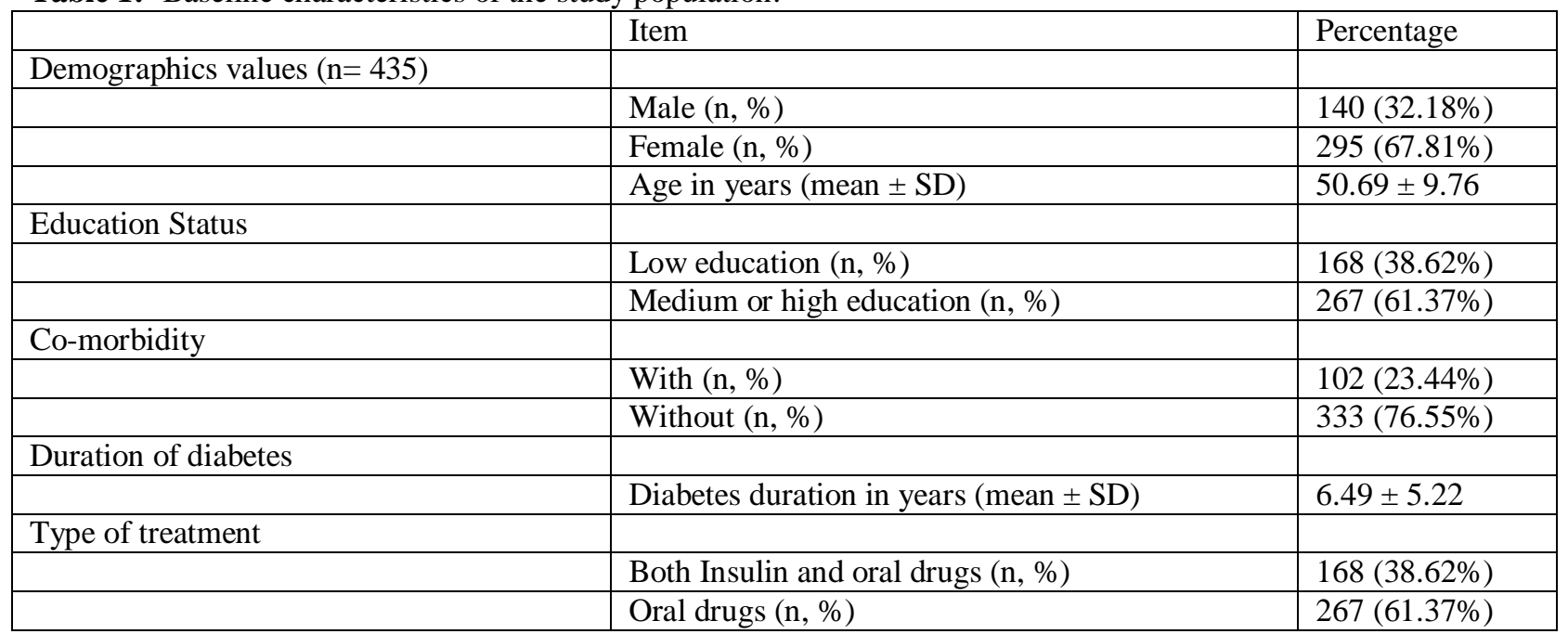

Note. SD (Standard Deviation); Co-morbidity (thyroidism, heart disease, hypertension and obesity); Low education is defined as no education or primary school; medium education is defined as vocational education; and high education is defined as secondary school and university.

Table 2:- Mean scores of depression and diabetes related emotional distress in type 2 diabetes mellitus.

\begin{tabular}{|l|l|l|}
\hline Variable & N & Mean \\
\hline Depression & 435 & $10.80 \pm 8.23$ \\
\hline Diabetes related emotional distress & 435 & $10.92 \pm 10.80$ \\
\hline
\end{tabular}

Table 3:- Showing correlation between depression and medication non-adherence among type 2 diabetic adults.

\begin{tabular}{|c|c|}
\hline \multicolumn{2}{|c|}{ Pearson's Correlation Coefficient } \\
\hline Variable & $\mathrm{r}=.733^{* *}(\mathrm{p}<.001)$ \\
\hline Diabetes related emotional distress & Depression \\
\hline
\end{tabular}

Table 4:- Stepwise regression analysis summary.

\begin{tabular}{|c|c|c|c|c|}
\hline Final model & $\mathrm{B}$ & $T$ & $p$ & R square \\
\hline \multicolumn{5}{|l|}{ Psychological variables } \\
\hline Diabetes related emotional distress & .696 & 22.30 & .000 & .540 \\
\hline \multicolumn{5}{|l|}{ Demographic and clinical variables } \\
\hline Gender & .060 & 1.83 & .067 & \multirow{6}{*}{.594} \\
\hline Age & .055 & 1.66 & .097 & \\
\hline Educational status & -.172 & -5.50 & .000 & \\
\hline Co-morbidity & .111 & 3.55 & .000 & \\
\hline Duration of Diabetes & .079 & 2.57 & .010 & \\
\hline Type of treatment & -.033 & -.950 & .343 & \\
\hline
\end{tabular}

\section{Discussion:-}

In the present study, the mean scores of depression and diabetes related emotional distress were $10.80 \pm 8.23$ and $10.92 \pm 10.80$ respectively. The prevalence of low depression and low diabetes related distress was lower than in other studies (Aikens, 2012; Pouwer, 2010; Egede and Zheng, 2003; Anderson, Freedland, Clouse, and Lustman, 2001; Peyrot et al., 1999; Hermanns, Kulzer, Krichbaum, Kubiak, and Haak, 2006). This might be due to differences in setting, assessment instruments or basic characteristics and differences of the study population.

Consistent with the previous literature associated factors for depression were educational status, comorbidity and duration of diabetes (Faber-Wildeboer, Os-Medendorp, Kooy, and Sol, 2013; Raval, Dhanaraj, Bhansali, Grover, and Tiwari, 2010; Niraula et al., 2013). And while controlling these variables in the model of stepwise multiple 
regression, diabetes related emotional distress emerged as significant predictor of depression in type 2 diabetes mellitus as has been reported previously (Faber-Wildeboer et al., 2013).

Several limitations of this study need to be mentioned. First, the cross-sectional study design means that it is not possible to draw long-term conclusions. Second, the samples were recruited from a general hospital and could not represent all of the patients in Kashmir.

Despite these limitations, the results of the present study are potentially of clinical value. In this study, according to the informed consent of the participants, the investigator reports all patients who were having high levels of depression or distress to their physicians. Subsequently, the physicians offered a selection of these patients (i.e. who were not receiving psychological care yet), a referral to a psychologist.

\section{Conclusion:-}

The mean score of depression and diabetes related emotional distress were $10.80 \pm 8.23$ and $10.92 \pm 10.80$ respectively among subjects with type $2 \mathrm{DM}$ in this study. Diabetes related distress, low educational status, comorbidity and short duration of diabetes were associated with the presence of depression. These findings support a recommendation for routine screening for depression in patients with diabetes mellitus, to reduce the number of the depressed or the misrecognized depressed diabetic patients and consequently offer them a better quality of life.

\section{Conflict of interest:-}

We declare that there is no conflict of interest on this research study. This research study did not receive fund or support from any source.

\section{References:-}

1. Aikens, J.E. (2012). Prospective associations between emotional distress and poor outcomes in type 2 diabetes. Diabetes Care, 35:2472-8.

2. Ali, S., Stone, M.A., Peters, J.L., Davies, M.J. and Khunti, K. (2006). The prevalence of co-morbid depression in adults with type 2 diabetes: A systematic review and meta-analysis. Diabet Med, 23(11):1165-73.

3. American Diabetes Association. Standards of medical care in diabetes-2006 (2006). Diabetes Care, 29(1):S442

4. Anderson, R.J., Freedland, K.E., Clouse, R.E. and Lustman, P.J. (2001). The prevalence of comorbid depression in adults with diabetes: A meta-analysis. Diabetes Care, 24(6):1069-78. Retrieved from http://dx.doi.org/10.2337/diacare.24.6.1069

5. Barlow, J., Wright, C., Sheasby, J., Turner, A. and Hainsworth, J. (2002). Self-management approaches for people with chronic conditions: A review. Patient Educ Couns., 48(2):177-87.

6. Beck, A.T., Steer, R.A. and Brown, G.K. (1996). Manual for Beck Depression Inventory (second edition). The psychological Corporation. Harcourt Brace and Company, San Antonio; 1996.

7. Black, S.A., Markides, K.S. and Ray, L.A. (2003). Depression predicts increased incidence of adverse health outcomes in older Mexican Americans with type 2 diabetes. Diabetes Care, 26(10):2822-8. Retrieved from http://dx.doi.org/10.2337/diacare.26.10.2822

8. Chew, B.H., Vos, R., Mohd-Sidik, S. and Rutten, G.E.H.M. (2016) Diabetes-Related Distress, Depression and Distress-Depression among Adults with Type 2 Diabetes Mellitus in Malaysia. PLoS ONE 11(3): e0152095. doi:10.1371/journal.pone.0152095

9. Ciechanowski, P.S., Katon, W.J., Russo, J.E. and Hirsch, I.B. (2003). The relationship of depressive symptoms to symptom reporting, self-care and glucose control in diabetes. Gen Hosp Psychiatry, 25(4):246-52. Retrieved from http://dx.doi.org/10.1016/S0163-8343(03)00055-0

10. Delahanty, L.M., Grant, R.W., Wittenberg, E., Bosch, J.L., Wexler, D.J., Cagliero, E. et al. (2007). Association of diabetes-related emotional distress with diabetes treatment in primary care patients with type 2 diabetes. Diabet Med., 24(1):48-54

11. Egede, L.E. and Zheng, D. (2003). Independent factors associated with major depressive disorder in a national sample of individuals with diabetes. Diabetes Care, 26(1):104-11. Retrieved from http://dx.doi.org/10.2337/diacare.26.1.104

12. Faber-Wildeboer, A.T., Os-Medendorp, H., Kooy, K., Sol, B.G.M. (2013). Prevalence and risk factors of depression and diabetes related emotional distress in patients with type 2 diabetes: A cross-sectional study. Journal of Nursing Education and Practice, 3(6). 
13. Fisher, L., Glasgow, R.E. and Strycker, L.A. (2010). The relationship between diabetes distress and clinical depression with glycemic control among patients with type 2 diabetes. Diabetes Care, 33:1034-6.

14. Fisher, L., Hessler, D.M., Polonsky, W.H. and Mullan, J. (2012). When is diabetes distress clinically meaningful? Establishing cut points for the diabetes distress scale. Diabetes Care, 35:259-64.

15. Fisher, L., Mullan, J.T., Arean, P., Glasgow, R.E., Hessler. D. and Masharani, U. (2010). Diabetes distress but not clinical depression or depressive symptoms is associated with glycemic control in both cross-sectional and longitudinal analyses. Diabetes Care, 33:23-8.

16. Fisher, L., Mullan, J.T., Skaff, M.M., Glasgow, R.E., Arean, P. and Hessler, D. (2009). Predicting diabetes distress in patients with type 2 diabetes: a longitudinal study. Diabet Med., 26:622-7.

17. Fisher, L., Skaff, M.M., Mullan, J.T., Arean, P., Mohr, D., and Masharani, U., et al. (2007). Clinical depression versus distress among patients with type 2 diabetes. Diabetes Care, 30:542-8

18. Gonzales, J.S., Delahanty, L.M., Safren, S.A., Meigs, J.B. Grant, R.W. (2008). Differentiating symptoms of depression from diabetes-specific distress: relationships with self-care in type 2 diabetes. Diabetologia, 51:1822-5.

19. Gonzales, J.S., Fisher, L. and Polonsky, W.H. (2011). Depression in diabetes: have we been missing something important? Diabetes Care, 34:236-9.

20. Gonzalez, J.S., Vileikyte, L., Ulbrecht, J.S., Rubin, R.R., Garrow, A.P., Delgado, C. et al. (2010). Depression predicts first but not recurrent diabetic foot ulcers. Diabetologia, 53(10):2241-8. Retrieved from http://dx.doi.org/10.1007/s00125-010-1821-x

21. Hermanns, N., Kulzer, B., Krichbaum, M., Kubiak, T. and Haak, T. (2006). How to screen for depression and emotional problems in patients with diabetes: comparison of screening characteristics of depression questionnaires, measurement of diabetes-specific emotional problems and standard clinical assessment. Diabetologia, 49:469-77.

22. Hermanns, N., Kulzer, B., Krichbaum, M., Kubiak, T. and Haak, T. (2006). How to screen for depression and emotional problems in patients with diabetes: Comparison of screening characteristics of depression questionnaires, measurement of diabetes-specific emotional problems and standard clinical assessment. Diabetologia, 49(3):469-77.

23. IDF (2010). Clinical Guidelines Task Force. Global guideline for type 2 diabetes: Recommendations for standard, comprehensive, and minimal care. Diabet. Med., 23:579-593. Retrieved from http://dx.doi.org/10.1111/j.1464-5491.2006.01918.x

24. Katon, W., von Korff, M., Ciechanowski, P., Russo, J., Lin, E., Simon, G., et al. (2004). Behavioral and clinical factors associated with depression among individuals with diabetes. Diabetes Care, 27(4):914-20. Retrieved from http://dx.doi.org/10.2337/diacare.27.4.914

25. King, H., Auburt, R.E., and Herman, W.H. (1998). Global burden of diabetes 1. 1995-2025: prevalence, numerical estimates, and projections. Diabetes Care, 21:1414-31.

26. Leach, L.S. (2012). Review: Major depression affects about $7 \%$ of adults aged 75 and above. Evid Based Ment Health, 15(3):64. Retrieved from http://dx.doi.org/10.1136/ebmental-2012-100694

27. Lloyd, C.E., Pambianco, G. and Orchard, T.J. (2010). Does diabetes-related distress explain the presence of depressive symptoms and/or poor self-care in individuals with type 1 diabetes? Diabet Med., 27:234-7.

28. Lustman, P.J. and Clouse, R.E. (2005). Depression in diabetic patients: The relationship between mood and glycemic control. J Diabetes Complications, 19(2):113-22. Retrieved from http://dx.doi.org/10.1016/S10568727(04)00004-2

29. Lustman, P.J., Anderson, R.J., Freedland, K.E., de Groot, M., Carney, R.M. and Clouse, R.E. (2000). Depression and poor glycemic control: A meta-analytic review of the literature. Diabetes Care, 23(7):934-42. Retrieved from http://dx.doi.org/10.2337/diacare.23.7.934

30. Nicolucci, A., Kovacs, Burns, K., Holt, R.I.G., Comaschi, M., Hermanns, N., Ishii, H., et al. (2013). Diabetes Attitudes, Wishes and Needs second study (DAWN2TM). Cross-national benchmarking of diabetes-related psychosocial outcomes for people with diabetes. On behalf of the DAWN2 Study Group, Diabet Med, 30:76777.

31. Niraula, et al. (2013). Prevalence of depression and associated risk factors among persons with type-2 diabetes mellitus without a prior psychiatric history: a cross-sectional study in clinical settings in urban Nepal. BMC Psychiatry, 13:309.

32. Peyrot, M., McMurry, J.F. and Krueger, D.F. (1999). A biopsychosocial model of glycemic control in diabetes: stress, coping and regimen adherence. J Health Soc Behav., 40:141-58.

33. Polonsky, W.H., Anderson, B.J., Lohrer, P.A., Welch, G., Jacobson, A.M., Aponte, J.E. et al. (1995). Assessment of diabetes-related distress. Diabetes Care 1995;18:754-760. 
34. Pouwer, F., Beekman, A.T., Lubach, C. and Snoek, F.J. (2006). Nurses' recognition and registration of depression, anxiety and diabetes-specific emotional problems in outpatients with diabetes mellitus. Patient Educ Couns, 60(2):235-40.

35. Pouwer, F., Beekman, A.T., Nijpels, G., Dekker, J.M., Snoek, F.J., Kostense, P.J. et al. (2003). Rates and risks for co-morbid depression in patients with type 2 diabetes mellitus: Results from a community-based study. Diabetologia, 46(7):892-8.

36. Pouwer, F., Beekman, A.T.F., Lubach, C. and Snoek, F.J. (2006). Nurses' recognition and registration of depression, anxiety and diabetes-specific emotional problems in outpatients with diabetes mellitus. Patient Educ Couns ., 60:235-40.

37. Pouwer, F., Geelhoed-Duijvestijn, P.H., Tack, C.J., Bazelmans, E., Beekman, A.J., Heine, R.J. et al. (2010). Prevalence of comorbid depression is high in out-patients with type 1 or type 2 diabetes mellitus. Results from three out-patient clinics in the Netherlands. Diabet Med, 27(2):217-24. Retrieved from http://dx.doi.org/10.1111/j.1464-5491.2009.02903.x

38. Raval, A., Dhanaraj, E., Bhansali, A., Grover, S., Tiwari, P. (2010). Prevalence \& determinants of depression in type 2 diabetes patients in a tertiary care centre. Indian J Med Res., 132:195-200.

39. Rubin, R.R., and Peyrot, M. (2001). Psychological issues and treatments for people with diabetes. J Clin Psychol., 57(4):457-78. Retrieved from http://dx.doi.org/10.1002/jclp.1041

40. Watson, D., Clark, L.A., Weber, K., Assenheimer, J.S., Strauss, M.E. and McCormick, R.A. (1995). Testing a tripartite model: I. Evaluating the convergent and discriminant validity of anxiety and depression symptom scales. J Abnorm Psychol., 104:3-14.

41. Zigmond, A.S. and Snaith, R.P. (1983). The hospital anxiety and depression scale. Acta Psychiatr Scand., 67:361-70. 